\title{
PERFORMANCE OF SOCIAL BENEFIT COMMITMENT IN MARKETING ORIENTATION
}

Silvije Jercinovic ${ }^{1,}$ MSc/ senior lecturer; Matija Muzina ${ }^{2,}$ student; Kristina Svrznjak ${ }^{3}$ Phd/ professor and Sandra Kantar ${ }^{4}$ Phd/ senior lecturer 1,2,3,4 Krizevci College of Agriculture, Croatia

\begin{abstract}
Market orientation today does not only imply on consumers and competition, but also on the wider socio-economic context. The purpose of this paper is to recognize the form of application of specific elements of market orientation in the specific circumstances of the Croatian agri-food sector and its impact on achieving competitive efficiency of their enterprises. The study was conducted on a sample made up of 83 agricultural and food enterprises from seven counties of continental Croatia. The research was carried out using the adjusted model of market orientation measurement, which includes an additional dimension focused on creating social benefits. The survey examined the attitudes of respondents regarding issues of enterprise's competitive performance, socially responsible marketing planning, information dissemination on social benefits and market research. The research results have shown that market research and socially responsible marketing planning have a positive impact, while the information dissemination on social benefits don't have a significant impact on the competitive efficiency of investigated enterprises.
\end{abstract}

Key words: market orientation, social benefit, competitive efficiency of enterprises.

JEL code: M31 O31, Q01, Q13

\section{Introduction}

Market orientation is a business approach or philosophy that focuses on identifying and meeting explicit or hidden needs or consumer desires. It could be also defined as a form of organizational culture in which employees continuously create top-notch value for consumers or as a set of marketing activities that lead to better performance.

Early founders of market orientation Narver and Slater (1990) have developed MKTOR model, and after them Jaworski and Kohli (1993) have developed their own model MARKOR. They have different approaches to market orientation. Kohli and Jaworski (1993) defined market orientation in the terms of organizational behaviour, related by principle of marketing concept, while Narver and Slater (1990) considered it in terms of organizational culture.

Given to the new conditions and to distribution of the roles in the socio-economic system, the emphasis is on socially responsible or sustainable business with its aim of achieving a sustainable society. It represents challenges and could make difficulties for them. In the case of classical market orientation, its models do not include orientation towards the broader socio-economic platform, which becomes an increasingly important factor in defining the conditions for achieving the competitiveness of the enterprises these days. Issues that are equally important in shaping enterprise programmes and strategies include a wide array of issues such as social issues, human rights, health, environmental issues etc. The mindset of contemporary settings for creating and implementing business models is, of course, achieving optimum and constant results through business, but considerable attention is also given to the impact on the development and well-being of the community in which the enterprises permanently and durably operate. Therefore, in measuring the factors that are conducive to achieving optimal business performance, it is necessary to include elements of sustainability. The concept of relation between corporate sector and society has been developed over the last couple of decades and expanded from social commitment and management to social responsibility and social response (Mbare, 2004). Therefore, the relationship between marketing and social factors is also interesting. The strategic aspects that arise from such a combination are becoming extremely popular and desirable and 
could be considered not only as a strategic positioning tool (Veludo-de-Oliveira, 2006), but also as an overall development tool of the company's competitiveness.

Social benefit as a new factor of market orientation can be defined as an increase in social welfare that is derived or resulted from a business activity. Social benefit is primarily tied to the delivery of values not only to the consumers, but also to the entire society. Social benefit is also a satisfaction with different aspects of life, so its concept can be linked even to the concept of quality of life (Christoph and Noll, 2003).

Social benefits in some way include those benefits that are delivered through production and delivery of products and services. It includes personal benefit to the individual and those benefits that are important for the society in general (Gunarathne, 2015).

Given the notion and importance of social benefit in the wider economic and social context, it is possible to make conclusions about its importance with regard to the potential that is attached to strategic marketing. This importance should be observed in the first place in the context of strategic planning, segmentation, product differentiation and of course, positioning.

The object of the paper is orientation towards social benefit within the model of market orientation.

The aim of the paper is to prove through the application of the social benefit into the market orientation that a such responsible business orientation has a favourable economic impact on the business outcomes, and therefore it is important to explore which of the emerging forms of implemented social benefit through market orientation are the best and to what extent affect the achievement of the enterprise's competitive efficiency.

The methods of research: analysis of scientific literature, the survey was conducted by employing the revised market orientation questionnaire NEWMKTOR (Gunarathne, 2015). SPSS was used for data analysis.

\section{Theoretical background}

From a marketing perspective, market orientation can be defined as one of the most important aspects of organizational culture. It is a system of common norms and beliefs, both of which can affect the organizational governance structure (Nuansate and Mohd Mokhtar, 2013). Organizational culture is created through organizational shared beliefs, values and guidelines by the enterprise's leadership and it is promoted among employees at all levels. So, it is very important moderator of the market orientation definition.

The philosophy of market orientation is based primarily on the principle of identifying needs and demands of consumers in order to achieve organizational goals and to achieve greater consumer satisfaction while simultaneously monitoring, recording and acknowledging competition activities. It is focused on the continuous adaptation of products and services according to the needs and expectations of consumers (Gronroos, 2006). The concept of market orientation focuses on coordinated business reporting and dissemination of data collected from the field (market), as well as responding to competition activities, all for the purpose of making effective business decisions. Conceptually, market oriented enterprises are well-informed about the market and have the ability to use this informative advantage to create excellent value for consumer (Gunarathne, 2015). The concept of marketing orientation suggests that the organisation, through collecting information, actually wants to find out about consumer requirements and how to prepare it adequately for responding to these requirements (Hyder and Chowdhury, 2015). 
It is well known that market orientation is treated as a very important component of enterprise survival capability (Neneh, 2016). As such, market orientation has been identified and recognized as a source of competitive advantage and is an important determinant of business success. Enterprises that have adopted and apply the concept of market orientation tend to be more efficient and have better market performance manifested through profitability, consumer retention rate, consumer satisfaction, innovation, sales rates and successful launch of new products (Gudlaugsson and Schalk, 2009). Also, through market orientation it is possible to achieve closer relationship with consumers, so it is possible to react quickly and flexibly to their desires and needs (Reijonen et al., 2012). Most of the researchers have found out the same, namely that market orientation has a positive effect on business performance, which is manifested through the development of new products, sales growth, profitability, return on investment (ROI) etc. First of all, market orientation is a factor in achieving organizational efficiency (Sin et al., 2005), which enables the enterprise to better understand its environment and especially consumers (Protcko and Dornberger, 2014). The impact of market orientation on the business performance of small and medium enterprises also represents researchers' interest (Mahmoud, 2011; Shehu and Mahmood, 2014). They concluded that the higher the level of market orientation, the higher the level of business performance of the company. Among other things, a significant correlation has been established between market orientation, organizational culture and business performance.

Although many measurement scales have been developed over the last twenty years for measuring market orientation, one of the most commonly used is the MKTOR scale developed by Slater and Naver (1993), which contains basic components: consumer orientation, competition orientation, and cross-functional co-ordination. Given the new socioeconomic circumstances that imply inclusion of components of social or ecological issues through socially responsible business policies in order to achieve sustainability in society and organization, it is obvious that the existing main market models of market orientation, including MKTOR, do not include according to their conceptual structure, validation of the mentioned elements. It is clear that demands and expectations related to the realization of the sustainability program have a strong impact on the business sector and represent an issue in terms of defining the position of corporate sector in wide society. Contemporary settings for creating and implementing business models are achieving optimum and constant results through usual business activities, but considerable attention is also paid to the development of community welfare for what is needed to be changed usual proceeding. Therefore, to achieve optimal business performance, it is essential to include elements of sustainability.

Based on the existing measuring scale developed by Slater and Naver (1993), new variable is added "Orientation to social benefit" into an existing model (Gunarathne, 2015). Conceptualization of a new model of market orientation named NEWMKTOR suggested by Gunarathne (2015) arose from MKTOR model. The new element of this model is " Orientation to social benefit " variable, with which it is possible to overcome the weaknesses of the existing model. NEWMKTOR model explains that orientation towards long-term profitability must be based on market orientation activities by thinking of a deeper and new way, which presumes orientation to society and nature.

During the development of the new model, the social responsibility and social marketing programme settings were applied, which broadly cover all the issues related to the sustainability. 


\section{Methodological background}

Sample. The study included 83 representatives of agricultural and food processing enterprises from seven counties of north-western Croatia. Of the total number of respondents, 57 were male $(69 \%)$, while 26 were women (31\%). On average, respondents had 28.5 years of work experience. The sample was dominated by small businesses ( $86 \%$ ). The sample contained unequal proportion of men (69\%) and women (31\%). All respondents were equally distributed in age ranges: 26 were younger than 30 year old; 28 were within the age range from $30-39 ; 28$ of them in age range from $40-49$, and 17 respondents were older than 50 years. Out of 83 respondents, 54 had high qualification level and 31 had high school education level. Of the total number of representative enterprises, 57 belonged to the food processing sector; 20 to the agriculture sector and 6 were mixed.

Instrumentation. Social benefit orientation was measured using the revised model of measurement of market orientation (NEWMKTOR) (Gunarathne, 2015), which includes new element of social benefits (Gunarathne, 2015). The NEWMKTOR measurement scale was created upon MKTOR model (Narver and Slater, 1990) by adding new group of items related to orientation to social benefits. It consisted of 29 items in three sub-scales representing four variables. This measurement scale represents the attitudes of respondents regarding the issues of competitive business efficiency, the implementation of the concept of socially responsible business, information dissemination on social benefits and market research. Responses were ranked on Likert's scale from one to five, where one meant totally disagree, and five fully agree with the statement. The items related to the enterprise's competitive performance represent the dependent variable (ECP). It consisted of six items measuring the effective business performance, differentiation versus competition, price positioning, negotiating ability in the procurement market, brand strength and corporate image. The questionnaire contained three independent variables as well: market research (MRS) with 8 items, information dissemination on social benefits (IDS) with 7 items and socially responsible marketing planning (SRM) with 7 items.

The reliability of a questionnaire was tested using Cronbach's alpha statistical method. The reliability of the dependent variable $(E C P)$ is considered reliable $(\alpha=0.940)$. The reliability of independent variables was determined too, for market research (MRS) $(\alpha=0.909)$, information dissemination on social benefits (IDS) $(\alpha=0.874)$ and socially responsible marketing planning (SRM) $(\alpha=0.652)$.

\section{Research results and discussion}

Values of arithmetic meanings are interpreted where it means $M>3.50$ exceptionally, $3.00<M$ $<3.49$ average, $M<3.00$ below average. The dependent variable of the enterprise's competitive performance was established on an average level $(M=3.22 ; S D=1.04)$, as well as independent variable socially responsible marketing planning $(\mathrm{M}=3.17 ; \mathrm{SD}=0.87)$. Independent variables market research $(M=3.60 ; s=0.97)$ and information dissemination on social benefits $(M=3.73$; $\mathrm{SD}=0.96$ ) they were above average.

In order to establish the initial relation, that is, the strength of the relation between the variables in the proposed model (dependent and independent variables), the correlation matrix is calculated, which shows which independent variables have the greatest influence on the dependent variable (Table 1 ). 
Correlation matrix of dependent and independent variables

Table 1

\begin{tabular}{|c|c|c|c|c|c|}
\hline & & ECP & IDS & MRS & SRM \\
\hline \multirow{4}{*}{ Pearson Correlation } & $\mathrm{ECP}$ & 1.000 & .034 & .533 & .434 \\
\hline & IDS & .034 & 1.000 & -.036 & -.106 \\
\hline & MRS & .533 & -.036 & 1.000 & .239 \\
\hline & SRM & .434 & -.106 & .239 & 1.000 \\
\hline \multirow{4}{*}{ Sig. (1-tailed) } & $\mathrm{ECP}$ & . & .381 & .000 & .000 \\
\hline & IDS & .381 & . & .374 & .169 \\
\hline & MRS & .000 & .374 & . & .015 \\
\hline & SRM & .000 & .169 & .015 & . \\
\hline \multirow{4}{*}{$\mathbf{N}$} & $\mathrm{ECP}$ & 83 & 83 & 83 & 83 \\
\hline & IDS & 83 & 83 & 83 & 83 \\
\hline & MRS & 83 & 83 & 83 & 83 \\
\hline & SRM & 83 & 83 & 83 & 83 \\
\hline
\end{tabular}

Source: author's calculations based on own research

From the correlation matrix it is evident that independent variables market research $(R=0.533$; $\mathrm{p}=0.000)$ and socially responsible marketing planning $(\mathrm{R}=0.434 ; \mathrm{p}=0.000)$ are statistically significantly correlated with the dependent variable. While on the other hand, independent variable information dissemination on social benefits $(R=0.034 ; p=0.381)$ it is not statistically significantly correlated with the dependent variable enterprise's competitive performance.

With the impact of variable market research on company's competitive performance a medium strong positive correlation was established $(R=0.533)$; therefore; it can be concluded that the importance of segmentation, consumer behaviour, competition, market influence, and factors affecting the enterprise's overall performance in terms of achieving competitiveness is of great importance. This means that marketing managers need to take care of all segments of research in the sense of achieving optimal marketing orientation, since only with the full knowledge of their own consumers, competition strategies as well as the legislative framework or changing market dynamics it will be possible to accurately adjust to all market demand.

Integration of social responsibility elements into business models is a relevant indicator of improving strategic and long-term business performance. Therefore, it is necessary that the conventional perspective of business model planning be improved with the inclusion of aspects of social, but also with other forms of sustainability, at all stages of their planning and implementation. Thus, it is possible to understand the notion of socially responsible marketing planning. A good number of existing business models are limited because they are focused on seeking short-term value-oriented revenue and therefore fail to promote business accountability (Porter and Kramer, 2011). Presenting solutions of the reduction of the company's negative impacts on society and the environment, benefits are gained for internal and external stakeholders such as suppliers, customers, consumers, the local community etc. (Bocken et al., 2014). In this case, for independent variable socially responsible marketing planning a relatively weak positive correlation has been established $(R=0.434)$. Although somewhat weaker in intensity, it is still strong enough to take into account its importance and impact on the development of competitiveness status.

In order to fully perform the regression analysis of the model, the indicators of regression representativeness of the total model had to be established (Table 2). 
Evaluation of the representativeness of the regression model

\begin{tabular}{|c|c|c|c|c|c|c|c|c|}
\hline \multirow[b]{2}{*}{$\mathbf{R}$} & \multirow[b]{2}{*}{$\mathbf{R 2}$} & \multirow{2}{*}{$\begin{array}{l}\text { Adjusted } \\
\quad \text { R2 }\end{array}$} & \multirow{2}{*}{$\begin{array}{c}\text { Estimate standard } \\
\text { error }\end{array}$} & \multicolumn{5}{|c|}{ Change Statistics } \\
\hline & & & & $\begin{array}{c}\text { R Square } \\
\text { Change }\end{array}$ & F Change & df1 & df2 & $\begin{array}{c}\text { Sig. F } \\
\text { Change }\end{array}$ \\
\hline $.625 *$ & .391 & .368 & .82413 & .391 & 16.903 & 3 & 79 & .000 \\
\hline
\end{tabular}

In this case, it was used adjusted determination coefficient $\mathrm{R}^{2} \mathrm{kor}=0.368$, which means that independent variables (3) explained $39 \%$ variance of dependent variable. Although it is desirable that the regression models explain as much as greater percentage of variance of the dependent variables, this value can be considered satisfactory and allows the representativeness of the model. The model is also statistically significant $(p=0.000)$.

In the next step, it is possible to show the final regression model, the way and the strength of the influence of independent variables on the enterprise's competitive performance (Table 3).

Coefficients of the regression model

Table 3

\begin{tabular}{|c|c|c|c|c|c|c|c|c|}
\hline & \multirow{2}{*}{ Model } & \multicolumn{2}{|c|}{$\begin{array}{c}\text { Non-standardized } \\
\text { coefficients }\end{array}$} & \multirow{2}{*}{$\begin{array}{c}\begin{array}{c}\text { Standardized } \\
\text { coefficients }\end{array} \\
\text { Beta }(B)\end{array}$} & \multirow{2}{*}{$\mathbf{t}$} & \multirow{2}{*}{ Sig. } & \multicolumn{2}{|c|}{$\begin{array}{l}95.0 \% \text { Confidence } \\
\text { Interval for B }\end{array}$} \\
\hline & & B & $\begin{array}{l}\text { Std. } \\
\text { Error }\end{array}$ & & & & $\begin{array}{l}\text { Lower } \\
\text { Bound }\end{array}$ & $\begin{array}{l}\text { Upper } \\
\text { Bound }\end{array}$ \\
\hline \multirow{4}{*}{1} & (Constant) & -.140 & .586 & & -.239 & .812 & -1.306 & 1.027 \\
\hline & IDS & .092 & .095 & .086 & .969 & .335 & -.097 & .281 \\
\hline & MRS & .485 & .096 & .456 & 5.046 & .000 & .294 & .677 \\
\hline & SRM & .399 & .109 & .334 & 3.672 & .000 & .183 & .615 \\
\hline
\end{tabular}

Source: author's calculations based on own research

From the enclosed table of coefficients of regression analysis, it is possible to notice that variables market research and socially responsible marketing planning have statistically significant influence on enterprise's competitive performance $(p=0.000)$. In the case of dependent variable, information dissemination on social benefits it is obvious that it doesn't have statistically significant influence on enterprise's competitive performance $(p=0.335)$.

Furthermore, a non-standardized coefficient (B) for independent variable market research is 0.485 . This means that each unit change of the independent variable market research increases the enterprise's competitive efficiency by 0.485 times.

Regression model suggests that in the case of independent variable socially responsible marketing planning its unit increase will boost the company's competitive performance by 0.399 times.

Influence of independent variable information dissemination on social benefits on enterprise's competitive performance is not significant, nor non-standardized regression coefficients (B) have no multiplying significance $(B=0.092)$. Also, any changes in its standard deviation will not significantly affect the change of the standard deviation of the dependent variable $(B=0.086)$.

\section{Conclusions, proposals, recommendations}

1) In the case of market orientation more pronounced elements of social benefit, the enterprise's competitive business efficiency is better. Namely, according to the conducted research and the proposed structure, it is evident that enterprises that promote and develop market research and conduct socially responsible marketing planning can have a significant impact on the development of their competitive performance. 
2) It can be concluded that enterprises need to invest in market research, consumer demand research, patterns of behaviour, competition, procurement market, recognition of potential and actual stakeholders that can affect business operations etc., in order to get wider perspective of possible stakeholder influences, which shape the organizational culture and help to understand external marketing environment.

3) Strategic marketing planning should involve as much elements of social responsibility as possible, but also ecological and economic as well. In such a case, besides the awareness of the company's representatives (owners or managers), it is also necessary to encourage education and training of employees for such understanding of marketing, towards increased adoption of a sustainability in all management patterns.

4) Information dissemination on social benefits for the stakeholders has almost no impact on the enterprise's competitive performance in the researched organisations. Therefore, management efforts in the future must be focused precisely on developing new innovative models of cooperation and sharing of business information with stakeholders.

5) In accordance with the principles of stakeholder theory, attitudes and opinions of wider number of involved stakeholders can be the basis for a more comprehensive and effective marketing strategy. Constant appreciation and communication with all stakeholders in the business environment must be developed or taken into account as one of the factors for creating of competitive enterprise.

\section{Bibliography}

1. Bocken, N.M.P. , Short, S.W.P., Rana, P. , Evans, S. (2014). A Literature and Practice Review to Develop Sustainable Business Model Archetypes. Journal of Cleaner Production, Volume 65, pp. 42 - 56.

2. Christoph, B., Noll, H. H. (2003). Subjective Well-Being in the European Union during the 90s'. Social Indicators Research, Volume 64, Issue 3, pp. 521 - 546.

3. Gronroos, C. (2006). On Defining Marketing: Finding a New Roadmap for Marketing. Management Theory, Volume 6, Issue 4, pp. $395-417$.

4. Gudlaugsson, T., Schalk, A. P. (2009). Effect of Market Orientation on Business Performance: Empirical Evidence from Iceland. The European Institute of Retailing and Services Studies, Volume 6, pp. 1 - 17.

5. Gunarathne, U. (2015). Measurement Model of the Market Orientation: New Theoretical Framework NEWMKTOR Model. International Journal of Management and Commerce Innovations, Volume 3, Issue 1, pp. $255-263$.

6. Hyder, A. S., Chowdhury, E. H. (2015). Market Orientation in Service Firms - An International Comparative Study. Procedia - Social and Behavioral Sciences, Issue 175, pp. 16 -23.

7. Jaworski, B. J, Kohli, A. K. (1993). Market Orientation: Antecedents and Consequences. Journal of Marketing, Volume 57, pp. 53 - 70.

8. Mahmoud, M. A., (2011). Market Orientation and Business Performance among SMEs in Ghana. International Business Research, Volume 4, Issue 1, pp. 241 - 251.

9. Mbare, O. (2004). The Role of Corporate Social Responsibility (CSR) in the New Economy. Electronic Journal of Business Ethics and Organization Studies, Volume 9, Issue 1. Retrieved: http://ejbo.jyu.fi. Access: 16.01.2018.

10. Narver, J. C. \& Slater, S. F., (1990). The Effect of Market Orientation on Business Profitability. Journal of Marketing, Volume 54, Issue 4, pp. 20 - 36.

11. Neneh, B. N. (2016). Market Orientation and Performance: The Contingency Role of External Environment. Environmental Economics, Volume 7, Issue 2, pp. 130 - 137.

12. Nuansate, S., Mohd Mokhtar, S. S. (2013). The Moderating Effect of Organizational Culture between Proactive Market Orientation and Hotel Business Performance in Thailand. Journal of Business and Economics, Volume 4, Issue 1, pp. 66 - 75.

13. Porter, M. E., Kramer M. (2011). Creating Shared Value: How to Reinvent Capitalism - and Unleash a Wave of Innovation and Growth. Harvard Business Review, Volume 89, pp. 62 - 77.

14. Protcko, E., Dornberger, U. (2014). The Impact of Market Orientation on Business Performance - The Case of Tatarstan Knowledge-Intensive Companies. Problems and Perspectives in Management, Volume 12, Issue 4, pp. $225-231$.

15. Reijonen, H., Laukkanen, T., Komppula, R., Tuominen, S. (2012). Are Growing SMEs More Market-Oriented and Brand-Oriented?. Journal of Small Business Management, Volume 50, Issue 4, pp. 699 - 716. 
16. Shehu, A. M., Mahmood, R. (2014). The Relationship between Market Orientation and Business Performance of Nigerian SMEs: The Role of Organizational Culture. International Journal of Business and Social Science, Volume 5, Issue 9, pp. 159 - 168.

17.Sin, L.Y.M., Tse, A.C.B., Heung, V. C.S., Yim, F. H.K. (2005). An Analysis of the Relationship between Market Orientation and Business Performance in the Hotel Industry. Hospitality Management, Volume 24, pp. 555-577.

18. Veludo de Oliveira, T. M. (2006). Society versus Business Organization: The Strategic Role of Marketing. Electronic Journal of Business Ethics and Organization Studies, Volume 11, Issue 1, pp. 26 - 29. 